\title{
SARS-CoV-2-Induced Vomiting as Onset Symptom in a Patient with COVID-19
}

\author{
Bao $\mathrm{Fu}^{1} \cdot$ Kun Qian ${ }^{2} \cdot$ Xiaoyun $\mathrm{Fu}^{1}$
}

Received: 9 April 2020 / Accepted: 17 April 2020 / Published online: 28 April 2020

○) Springer Science+Business Media, LLC, part of Springer Nature 2020

Keywords SARS-CoV-2 · COVID-19 · Gastrointestinal symptoms · Vomiting

\section{Introduction}

The two recent reports by Xiao et al. [1] and Song et al. [2] concerned SARS-CoV-2-induced diarrhea in patient with COVID-19. The typical symptoms at onset of illness included fever, dry cough, fatigue, myalgia, and dyspnea [3]. Patients with gastrointestinal tract symptoms alone as onset symptom are very rare. Here, we reported SARS$\mathrm{CoV}$-2-induced vomiting as onset symptom in a patient with COVID-19.

\section{Case Report}

On February 7, 2020, a 68-year-old male was admitted to hospital for "paroxysmal vomiting for 7 days, fever for 1 day". The patient developed paroxysmal vomiting 7 days ago. He bought antiemetic at the pharmacy, and his vomiting symptoms eased slightly after taking the antiemetic. One day before admission, he had a fever with a temperature of $38.0^{\circ} \mathrm{C}$. He has no history of exposure to Wuhan, but his nephew had a history of exposure to Wuhan. On admission, his chest CT showed pneumonia in the bilateral lungs and ground-glass opacities in the right lung. We suspected that he was infected with SARS-CoV-2. A pharyngeal swab sample and stool sample were collected. On admission, the count of total T lymphocyte decreased and IL-6 slightly increased.

Bao Fu

fubao0607@126.com; zyyxyfxy@163.com

Xiaoyun $\mathrm{Fu}$

kun@vip.163.com

1 Department of Critical Medicine, Affiliated Hospital of Zunyi Medical University, Zunyi 563000, China

2 Radiology Department, Affiliated Hospital of Zunyi Medical University, Zunyi 563000, China
There were no obvious abnormal in hepatic function and renal function (Fig. 1 and Table 1).

On February 8, 2020, real-time reverse transcriptase polymerase chain reaction (rRT-PCR) of the pharyngeal swab and stool sample were both positive for SARS-CoV-2. He still had vomiting symptom after admission, without diarrhea, cough, dyspnea or chest pain. He was given antiviral therapy, including $\alpha$-interferon atomization inhalation (5 million $\mathrm{U}$ per time, Bid), oral lopinavir/ritonavir (2 capsules each time, Bid) and ribavirin $500 \mathrm{mg}$ (intravenous infusion, Bid). Xuebijing (100 ml, Bid) and Chinese herb were also used. After treatments, his body temperature of patient was normal, and his vomiting gradually disappeared. On $26 \mathrm{Feb}-$ ruary and 29 February, rRT-PCR of the pharyngeal swab and stool sample were both negative. The result of CT scan on 26 February showed that the inflammation was significantly decreased in the bilateral lungs and the ground-glass opacities in the right lung had resolved. Now, he was discharged and returned home.

\section{Discussion}

A kind of novel coronavirus (2019-nCoV) pneumonia broke out in Wuhan, Hubei province of China, in early December 2019 and has been declared the sixth public health emergency of international concern by the World Health Organization. Subsequently, this pneumonia was named coronavirus disease 2019 (COVID-19). The most common symptoms were fever ( $43.8 \%$ on admission and $88.7 \%$ during hospitalization) and cough (67.8\%), while diarrhea was uncommon (3.8\%) [4]. Some studies have reported SARSCoV-2-induced diarrhea, but there have been fewer reports of vomiting.

It has been proven that SARS-CoV-2 uses the angiotensin-converting enzyme 2 (ACE2) as a viral receptor to enter 


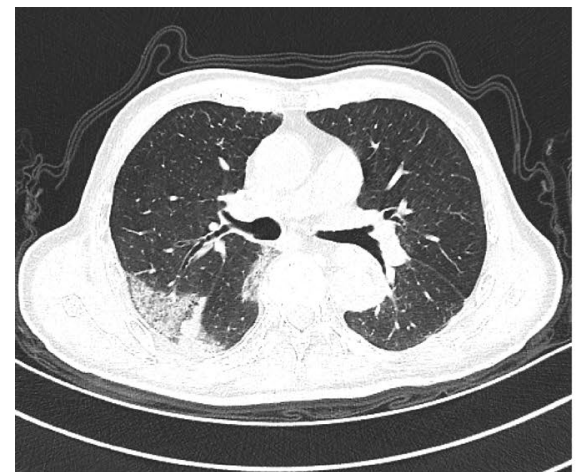

7 February

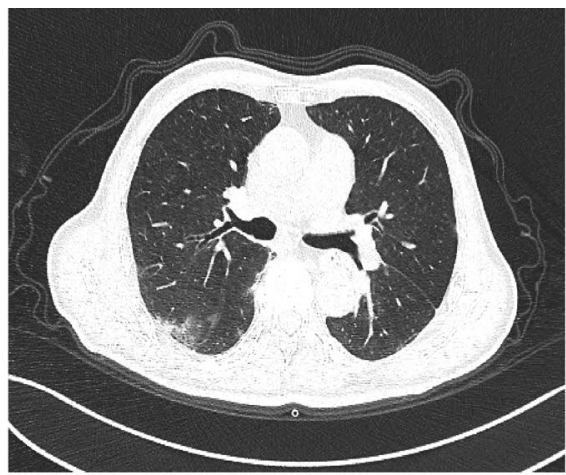

16 February

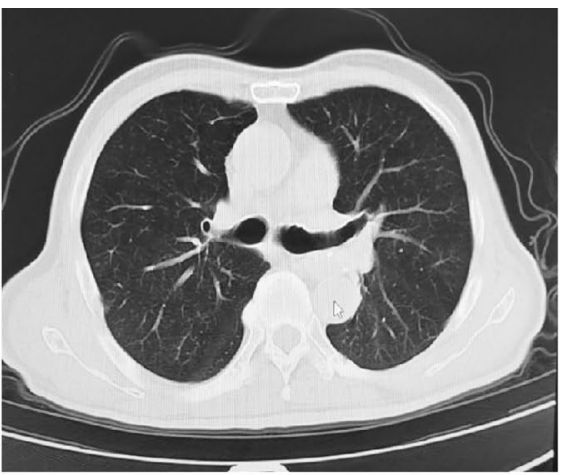

26 February

Fig. 1 Chest CT images. The images showed the ground-glass opacities in right lung

Table 1 Clinical laboratory results of the patient

\begin{tabular}{llc}
\hline Measure & Patient results (hospital day 2) & Normal range \\
\hline White blood cell count $\left(10^{9} / \mathrm{L}\right)$ & 6.45 & $3.5-9.5$ \\
Neutrophil count $\left(10^{9} / \mathrm{L}\right)$ & 4.64 & $1.8-6.3$ \\
Lymphocyte count $(109 / \mathrm{L})$ & 0.88 & $1.1-3.2$ \\
Total T lymphocyte $(\%)$ & 48 & $50.0-84.0$ \\
Absolute value of total T lymphocyte $(\mu \mathrm{L})$ & 475 & $955-2860$ \\
T helper cell $(\%)$ & 37 & $27.0-51.0$ \\
T helper cell absolute value $(\mu \mathrm{L})$ & 366 & $550-1440$ \\
T suppressor cell $(\%)$ & 12 & $15.0-44.0$ \\
T suppressor cell absolute value $(\mu \mathrm{L})$ & 114 & $320-1250$ \\
T helper cell/T suppressor cell & 3.08 & $0.71-2.78$ \\
Aspartate transaminase $(\mathrm{U} / \mathrm{L})$ & 31 & $13-35$ \\
Alanine transaminase $(\mathrm{U} / \mathrm{L})$ & 19 & $7-40$ \\
Total bilirubin $(\mu \mathrm{mol} / \mathrm{L})$ & 10.5 & $5-21$ \\
Creatinine $(\mu \mathrm{mol} / \mathrm{L})$ & 56 & $30-90$ \\
Urea nitrogen $(\mathrm{mmol} / \mathrm{L})$ & 6.15 & $2.8-7.2$ \\
Uric acid $(\mu \mathrm{mol} / \mathrm{L})$ & 114 & $155-357$ \\
Creatine kinase $(\mathrm{U} / \mathrm{L})$ & 203 & $26-140$ \\
CK-MB $(\mathrm{U} / \mathrm{L})$ & 15 & $0-24$ \\
Hypersensitive C-reactive protein $(\mathrm{mg} / \mathrm{L})$ & 83.5 & $0.068-8.2$ \\
IL-2 $(\mathrm{pg} / \mathrm{mL})$ & 1.17 & $0.08-5.71$ \\
IL-4 $(\mathrm{pg} / \mathrm{mL})$ & 2.76 & $0.10-2.80$ \\
IL-6 $(\mathrm{pg} / \mathrm{mL})$ & 18.20 & $1.18-5.30$ \\
TNF- $\alpha(\mathrm{pg} / \mathrm{mL})$ & 2.68 & $0.10-2.31$ \\
IFN- $\gamma(\mathrm{pg} / \mathrm{mL})$ & 1.60 & $0.16-7.42$ \\
\hline & &
\end{tabular}

the target cell [5]. Except for the respiratory system, ACE2 receptors are highly abundantly expressed in the glandular cells of gastric, duodenal, and rectal epithelia [6]. Therefore, SARS-CoV-2 binds to the ACE2 receptor that is abundantly expressed in gastrointestinal system as a possible reason for gastrointestinal infection [7]. ACE2 is considered as an important regulator of intestinal inflammation, which may be the potential mechanism by which diarrhea in COVID19 is caused. After viral entry, virus-specific RNA and proteins are synthesized in the cytoplasm to assemble new virions, which can be released to the gastrointestinal tract [1]. Isolated infectious SARS-CoV-2 from stool indicates the possible fecal-oral transmission route of SARS-CoV-2 [1]. SARS-CoV RNA was found in the sewage water of two hospitals in Beijing treating patients with SARS [8]. Therefore, fecal-oral transmission may be another route for SARS-CoV-2 spread. Prevention of fecal-oral transmission should be taken into consideration to control the spread of 
SARS-CoV-2. Although SARS-CoV2 RNA is detectable in stool samples, confirmation of viability from viral culture is lacking.

Currently, SARS-CoV-2 is breaking out in the worldwide. Patients initially presented with only vomiting are easily misdiagnosed or missed. Therefore, the gastrointestinal symptoms caused by SARS-CoV-2 should be paid attention to. In China, rRT-PCR testing for SARS-CoV-2 from stool is performed routinely in patients and is used as guidance for the disposition of patients with COVID-19.

Acknowledgments Not applicable.

Author's contribution XYF conceived and designed the study. BF contributed to the writing and checking of the letter. KQ contributed to provide the image of chest CT.

Funding Not application.

\section{Compliance with Ethical Standards}

Conflict of interest The authors declare that they have no conflict of interest.

Ethics approval Not applicable.

Patient and public involvement Patients and/or the public were not involved in the design, or conduct, or reporting, or dissemination plans of this research.

Patient consent for publication Not required.

Provenance and peer review Not commissioned; externally peer reviewed.

\section{References}

1. Xiao F, Tang M, Zheng X, Liu Y, Li X, Shan H. Evidence for gastrointestinal infection of SARS-CoV-2. Gastroenterology. 2020 https://doi.org/10.1053/j.gastro.2020.02.055.

2. Song Y, Liu P, Shi XL, et al. SARS-CoV-2 induced diarrhoea as onset symptom in patient with COVID-19. Gut. 2020. https://doi. org/10.1136/gutjnl-2020-320891.

3. Wang D, Hu B, Hu C, et al. Clinical characteristics of 138 hospitalized patients with 2019 novel coronavirus-infected pneumonia in Wuhan, China. JAMA. 2020. https://doi.org/10.1001/ jama.2020.1585.

4. Guan WJ, Ni ZY, Hu Y, et al. Clinical characteristics of coronavirus disease 2019 in China. New Engl J Med. 2020. https://doi. org/10.1056/NEJMoa2002032.

5. Zhou P, Yang XL, Wang XG, et al. A pneumonia outbreak associated with a new coronavirus of probable bat origin. Nature. 2020;579:270-273.

6. Harmer D, Gilbert M, Borman R, Clark KL. Quantitative mRNA expression profiling of ACE 2, a novel homologue of angiotensin converting enzyme. FEBS Lett. 2002;532:107-110.

7. Ong J, Young BE, Ong S. COVID-19 in gastroenterology: a clinical perspective. Gut. 2020. https://doi.org/10.1136/gutjnl-2020321051.

8. Wang XW, Li J, Guo T, et al. Concentration and detection of SARS coronavirus in sewage from Xiao Tang Shan Hospital and the 309th Hospital of the Chinese People's Liberation Army. Water Sci Technol. 2005;52:213-221.

Publisher's Note Springer Nature remains neutral with regard to jurisdictional claims in published maps and institutional affiliations. 